\section{The effect of organizational studies on financial risk measures estimation}

\author{
Marcelo Brutti Righi ${ }^{1}$ \\ Fernanda Maria Müller1 \\ ${ }^{1}$ Federal University of Rio Grande do Sul, School \\ of Administration, Porto Alegre, Brazil \\ Vinícius Girardi da Silveira ${ }^{2}$ \\ ${ }^{2}$ Agência da Previdência Social, Uruguaina, Brazil \\ Kelmara Mendes Vieira ${ }^{3}$ \\ ${ }^{3}$ Federal University of Santa Maria, Department \\ of Administration, Santa Maria, Brazil
}

Received on

08/25/2017

Approved on

06/27/2018

\section{Responsible editor:}

Prof. Dr. Javier Montoya del

Cort

\section{Evaluation process:}

Double Blind Review

\title{
Abstract
}

Purpose - The objective of this research is to establish a link between risk models and the paradigms of organizational studies.

Design/methodology/approach - To achieve this goal, a discussion about risk in organizations was presented, based on organizational studies. Additionally, an illustration was provided to evaluate how organizational paradigms influence risk models.

Findings - There are three main organizational perspectives: Modernist, Postmodernist, and Neo-modernist. Based on the empirical analysis, it was observed that the use of unrealistic assumptions (Modernist perspective) in risk management increases model risk, and is thus not suitable for risk model estimation. However, the absolute lack of measurement of the Postmodernist paradigm can be too radical in the sense that, in the practical field, there is a crucial need for quantitative information to enable financial institutions and investors to protect their investments. Thus, it was found that the solution is the Neomodernist paradigm, which employs more realistic assumptions about data behavior.

Originality/value - The main contribution of this research is to raise the influence of other attributes of financial risk estimation that go beyond mathematical and statistical grounds. Previous studies do not relate the traditional literature on financial risk management estimation with literature focused on the sociological issues of organizational studies. Hence, this study can help build a bridge for future integration between these two related research subjects.

Keywords - Organizational Studies; Risk Models; Risk Management; Model Risk.

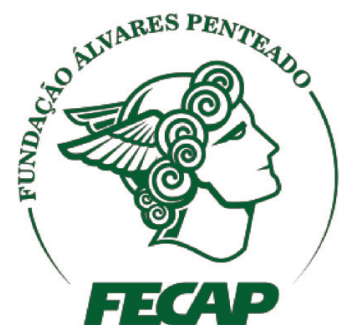

\section{Review of Business} Management

DOI: $10.7819 /$ rbgn.v0i0.3953 


\section{Introduction}

Risk is one of the most important financial concepts, perhaps the most important. Every time financial stress occurs, including the recent crises and collapses in the financial system, the focus on risk management is raised. One fundamental aspect of proper financial risk management is risk measurement, especially accurate risk measures forecasting. This importance is not just related to the possibility of huge losses, which would be a great motivation, but is also linked to regulation (Daníelsson, James, Valenzuela, \& Zer, 2016; Müller \& Righi, 2018). The overestimation of risk can make a financial institution retain many resources that could be applied in other investments, generating opportunity costs, while underestimating risk can simply be catastrophic, especially in times of crisis.

Risk measures are theoretical concepts. For real applications, it is necessary to take an estimation approach to computing them. Although there are studies that compare models, there is no consensus regarding the best approach or even a ranking of model performance, because no model is a warranty for success in risk modeling ${ }^{1}$. For risk forecasting, it is necessary to use a model that is estimated with market data. This requires several assumptions regarding model design and the statistical properties of the data. It is impossible to create a perfect risk model; a risk forecaster must weigh the pros and cons of various models and data choices to create what may inevitably only be an imperfect model (Daníelsson, 2002). From a general point of view, there are still many practical shortcomings in risk measures estimation (Berkowitz \& O'Brien, 2002; Pérignon, Deng, \& Wang, 2008; Pérignon \& Smith, 2010).

As the financial system becomes more complex, the need for complicated statistical models to measure risk and to price assets becomes greater. Unfortunately, the reliability of such models decreases with complexity. In periods of greater instability, the models tend to be least reliable. This occurs because the fundamental assumption in most statistical risk modeling is that the basic statistical properties of financial data during stable periods remain (almost) the same as during crisis periods (Daníelsson, 2002; Daníelsson, 2008). In this modeling, the quality of the assumptions is of key importance. In financial modeling, many potentially important factors must be considered in the choice of the model, so it presents results that are closer to reality. For example, financial time series display important stylized facts, including non-linearity, asymmetry, serial dependence, and the heavy-tails of financial assets marginal and joint probability distribution, which cannot be ignored in the estimation process. The uncertainty present in this process, related to the choice of model and specification, is mentioned in the literature as model risk (Boucher, Daníelsson, Kouontchou, \& Maillet, 2014; Daníelsson et al. 2016).

Another difficulty for risk modeling is that, in finance, the statistical properties of the phenomena being modeled change under observation. This is because rational market participants react to information and, by reacting, directly affect what is being observed. Outcomes in financial markets represent the aggregate strategic behavior of many individuals with different abilities and objectives. One can only model aggregate behavior. Financial modeling changes the statistical laws governing the financial system in real-time, leaving the modelers to play catchup. This becomes especially pronounced when the financial system hits a crisis (Daníelsson, 2008; Daníelsson et al. 2016). This is a phenomenon that Daníelsson and Shin (2003) call endogenous risk. Normally, when everything is calm, one can ignore endogenous risk, but in periods of crisis, the models fail.

In such a climate of indeterminacy, it is unsurprising that the public has become more skeptical of expert systems and more willing to challenge specialist opinion on risk issues. Risk practitioners are now more aware they must accurately assess adverse effects, while 
understanding the subjective processes by which people make sense of risk. It is thus reasonable to argue that techno-scientific development in Western cultures has produced something of a double-edged sword. On one hand, one can identify a greater range of social risks than in previous eras. However, the increasing sophistication of scientific and technological tools allows us to identify risks that would have remained unknown in the past (Mythen, 2008).

With this in mind, in recent years, more flexible risk models have been proposed in the literature. Such models are used by the industry with success, in comparison with unreliable techniques. Research by Kuester, Mittnik, and Paolella (2006), Alexander and Sheedy (2008), Berkowitz, Chen, and Tu (2013), Christoffersen and Pelletier (2011) and Müller and Righi (2018), in comparisons of risk estimation techniques, have pointed out that methods that consider realistic properties of financial data frequently have the best performance. The evolution and construction of these models have mathematical motivations regarding financial risk management. This field is constructed by developing methods and techniques that consider economic and financial empirical facts developed over time through research. There is also an epistemological reasoning behind this evolution of models, ranging from unrealistic to realistic approaches. This is related to organizational studies and the paradigms of business management and social sciences as a whole. One can, at least from an abstract perspective, to understand unreliable models as a Modernist approach and recent flexible models as a Neo-modernist approach.

The inclusion of organizational studies in this discussion is not surprising. Organizations are not only seen as producers of risks borne by other actors, but they have also become bearers of regulatory, legal, and reputational risks, as governments and other stakeholders increasingly target them in their efforts to manage the risks inherent to organizing. Inside the organization, the discourse of risk and its management has become a source of principles for organizing and managing with important implications for how organizations are represented, managed, and governed, and for how they respond to actors in their environment (Power, 2007). No longer the sole purview of those working in finance and insurance, issues of risk and its management increasingly inform managerial decision-making in all sectors of the economy. Ideas about risk and risk management play a key role in organizing and organization (Scheytt, Soin, Sahlin-Andersson, \& Power, 2006).

Considering this perspective, the objective of this study is to establish a link between risk models and the paradigms of organizational studies. To that end, a discussion is exposed regarding the topic of risk in organizations, based on organizational studies to support the study idea. Additionally, an illustration is presented with real data to show how risk models are influenced by organizational paradigms and the way this affects estimation results. Based on this illustrative example, it can be identified if the paradigm adopted increases model risk. In this study, similarly to the definition used by the Federal Reserve (2011), model risk refers to losses from the use of an incorrect model and from uncertainty present in the estimation process.

The main contribution of this research is to raise the influence of other attributes of financial risk estimation that go beyond mathematical and statistical grounds. Previous studies do not relate the traditional literature on financial risk management estimation with literature focused on the sociological issues of organizational studies. Hence, this study can help build a bridge for future integration between these two related research subjects.

The remainder of this paper is structured as follows. Section 2 presents a review of risk analysis from the organizational perspective. Section 3 describes the risk measures used in this paper and the estimation methods, as well as empirical results regarding statistical and paradigmatic comparisons of models. Section 4 summarizes and concludes the research. 


\section{Risk from the Organizational Perspective}

The growth in the importance of financial markets has been accompanied by the rise of financial economics as an academic discipline. This discipline is characterized by the mathematically rigorous analysis of markets assumed to be relatively free of imperfections. Perhaps the most important concept in finance, at least regarding such rigorous analysis, is risk. Goede (2004) argues that, in the finance domain, complex risk management facilitates financial risk-taking by insulating financial decision-making against failure.

Although risk has conventionally been approached in the natural sciences as an object to be technically mastered by mathematical probability, since the early 1980 s, social scientists have focused on the subjective and social dimensions of risk (Mythen, 2008). Risk is no longer the exclusive preserve of scientists and technocrats, but is fast becoming the "lingua franca" of business management and even public policy. Regarding this dissemination, Luhmann (1998) says that the particular success of risk in extending its realm over more areas of life is explained by the tendency of modern societies to experience their future in terms of decisional uncertainties. Corroborating this idea, Coles, Smith, and Tombs (2000), and Hutter and Power (2005) argue that the concept of risk has assumed a prominent position within the social sciences and business practice. According to Power (2004), we are not only living in a Risk Society, but there is also concern about the risk management of everything. As confirmed by Rothstein, Huber, and Gaskell (2006), the focus of this argument is not whether there has been a change in the actual risks faced by society but whether there has been a change in how events are framed and managed as risks.

The concept of risk is subject to organizational paradigms based on sociological reasoning. The traditional paradigm that emerged after the Enlightenment is Modernism. In Modernity, the world was seen as governed by laws of probability, and risk was viewed as a straightforward matter that was measurable and calculable (Gephart, Maanen, \& Oberlechner, 2009). Risk was defined in statistical terms as the probability of an event multiplied by the magnitude of losses or gains associated with the event (Lupton, 1999). This view of risk served an important function for enabling the industrial system to deal with its own unforeseeable future (Beck \& Holzer, 2007).

Under Modernism, risk is amenable to quantification by a distribution of probabilistic outcomes. Objective quantification makes risks commensurable and allows them to be used for decision-making, including asset pricing, risk analysis in capital investment, and hedges. Proof of this is that researchers, such as Lubatkin and Rogers (1989) and Woo and Cool (1990), have often adopted the shareholder value-creation perspective in their theoretical arguments concerning risk and in their choice of risk measures, such as systematic and unsystematic risk, based on the capital asset pricing model.

An interesting Modernist perspective on risk derives from cognitive science. This approach, defended by Kunreuther and Slovic (1996), Lee, Kozar, and Larsen (2003), and Tversky and Kahneman (1974), among others, has influenced organizational research. According to Lupton (1999), cognitive science links hazards with calculations and states that risk is conceived as an objective phenomenon, i.e., it is assumed to exist in real form in the world. Based on this perspective, risk can be assessed by determining the real probability of an adverse event multiplied by the true magnitude and severity of the consequences. According to Miller (2009), risk research from a Modernist perspective focuses primarily on individuals, treats risk preferences as exogenously given, attempts to quantify it, assumes that risk reflects a probability distribution, omits ethical considerations, and neglects actions by focusing on decision-making. Overall, Modernist 
assumptions are often taken for granted, rather than being explicitly acknowledged and defended.

A set of challenges to Modernism arose in the latter half of the last century, and a Postmodernist paradigm has found its place. The Postmodernist is critical of the Modernist approach, rejecting aspirations of objectivity and certainty in knowledge and rationality (Miller, 2009). Other aspects of the critique of Modernism include conformity (Mirchandani, 2005), the rejection of subject-centered reasoning, referential use of language, and atomism and reductionism in metaphysics. According to Lyotard (1984) and Schrag (1989), some of the main themes of the Postmodern alternative to Modernism are: i) Moving away from the individual as the starting point for epistemology; ii) Acknowledging the social basis for rationality and ethics; iii) Recognizing the role of power in claims of knowledge and rationality; iv) Appreciating the limitations of language and the pervasiveness of hermeneutics; and v) Rejecting metanarratives, in favor of local, situated accounts.
This Postmodernist perspective is also called sociocultural research. Lupton (1999) classified sociocultural perspectives on risk into three streams:

i) The cultural/symbolic perspective of Douglas and Wildavsky (1982), based on anthropology, examines how social contexts generate risk judgments. According to this view, risk is never fully objective or knowable outside of belief systems and moral positions.

ii) The risk society perspective of sociologists, such as Beck (1992) and Giddens (2013), elaborates on how industrialization has produced systemic risk in late modernity.

iii) Governmentality research, defended by Castel (1991) and Dean (1999), among others, draws on the writings of Michel Foucault to understand discourses, practices, and institutions associated with regulating risk in society.

Table 1 summarizes the distinctions between Modernist and Postmodernist assumptions, according to Miller (2009).

Table 1

\section{Contrasting Modernist and Postmodernist assumptions regarding risk management, adapted from Miller (2009)}

\begin{tabular}{lll}
\hline Dimensions of contrast & Modernist Assumptions & Postmodernist Assumptions \\
\hline $\begin{array}{l}\text { Unit of analysis } \\
\text { Risk preferences }\end{array}$ & $\begin{array}{l}\text { The individual is the primary unit of analysis for } \\
\text { understanding organizational risk. } \\
\text { Risk preferences are given and left unexplained. }\end{array}$ & $\begin{array}{l}\text { Risk is a social and multilevel phenomenon. } \\
\text { Risk preferences, perceptions, and responses are } \\
\text { Risk quantification }\end{array}$ \\
$\begin{array}{l}\text { Nature of the } \\
\text { environment }\end{array}$ & $\begin{array}{l}\text { Risk is objectively quantifiable. } \\
\text { Ethics }\end{array}$ & $\begin{array}{l}\text { Risk is subjective and unquantifiable. } \\
\text { The environment is a complex, socially constructed }\end{array}$ \\
Risk responses & Ethical considerations are omitted. & $\begin{array}{l}\text { system. } \\
\text { Ethical considerations are integral to risk assessment } \\
\text { and management. }\end{array}$ \\
& $\begin{array}{l}\text { Decisions are the key way that organizations } \\
\text { respond to risk. }\end{array}$ & Actions, not just decisions, respond to risk.
\end{tabular}

The content of Table 1 summarizes the main distinctions regarding Modernist and Postmodernist perspectives. Modernism focuses risk on individuals in a restrictive and quantitative way, ignoring social and ethical aspects.
Postmodernism is the opposite, with its societybased perspective in which risk is unquantifiable and replete with ethical implications. As argued by Miller (2009), these themes reflect a shift in the locus of knowledge, rationality, and ethics 
from the individual to the community, and an appreciation for social processes. Additionally, there is also a Neo-modernist perspective. This approach combines insights from social sciences and the rigor of the methods associated with these social sciences.

\section{Risk Models: From Unrealistic to Realistic Assumptions}

This section presents estimation models for the most used risk measures, Value at Risk (VaR) and Expected Shortfall (ES), with the purpose of comparing some properties of these models. The objective is to construct links between the usual statistical comparisons and the previously presented organizational paradigms. For a better understanding, this section is divided into three parts: i) Risk measures background; ii) Risk models and empirical data; and iii) Statistical and paradigmatic comparisons of models.

\section{I Risk measures background}

Consider a one-period framework, which means one that has the current date 0 and a future date $T$. No trading is possible between 0 and $T$. Consider the random payoff $X$ of some asset or portfolio (that is, the random profit if $X \geq 0$, or loss if $X<0$ ), defined in a probability space $(\Omega, F, P)$. To avoid tedious mathematical treatment, it is assumed that $X_{t}$ is a $p$-integrable random variable. $X$ can be treated as an element of the space $L^{p}(\Omega, F, P)$, for $1 \leq p \leq \infty$. This space is common in risk management (see Föllmer and Weber (2015)). Measuring risk is thus equivalent to establishing a correspondence $\rho(X)$ between the space of $X$ and the set of real numbers, i.e., $\rho: L^{p} \rightarrow R$.

Based on this framework, VaR and ES are defined, which are the most common risk measures employed nowadays. $\mathrm{VaR}$ is the maximum loss that is expected for a given significance level and period; while ES is the expected value of losses that exceed $\alpha$ - quantile of interest, i.e., VaR losses. VaR has become the standard measure for financial market risk because of its simplicity of understanding and implementation. However, $\mathrm{VaR}$ is not a coherent risk measure ${ }^{2}$, in the sense proposed by Artzner, Delbaen, Eber, and Heath (1999), and it ignores the potential of losses beyond the quantile of interest. ES as a risk measure overcomes these shortcomings because it considers the expected value of losses beyond the quantile of interest, and it fulfills coherence axioms. More details are found in Acerbi and Tasche (2002), Rockafellar and Uryasev (2002), and Tasche (2002).

So, consider $X$ as a stationary process with the stationary distribution function $F$. Given a value $\alpha \in(0,1)$, generally close to zero, the $\mathrm{VaR}$ at a significance level $\alpha$ is the quantile $q_{\alpha}$ of $F$ for this level. When dealing with short positions, should be considered with the corrected signal $-X$ instead of $X$. Mathematically, VaR is defined as (1).

$$
\operatorname{VaR}^{\alpha}=q_{\alpha}(X)=\inf \{q: F(q) \geq \alpha\} .
$$

Based on this definition, one can note that $\mathrm{VaR}$ does not consider information after the quantile of interest, only the point itself. As explained, ES can overcome this drawback. ES at significance level $\alpha$ is then the expectation of $\mathrm{X}$, once $\mathrm{X}$ is below $\mathrm{VaR}$ for this level, i.e., an extreme loss. Formally, formulation (2) defines ES.

$$
E S^{\alpha}=E\left[X \mid X<\operatorname{VaR}^{\alpha}=q_{\alpha}(X)\right]=\alpha^{-1} \int_{0}^{\alpha} q_{s}(X) d s .
$$




\subsection{Risk models and empirical data}

For the empirical analysis, the S\&P $500^{3}$ index daily closing price data was used, covering January 2000 to December 2012. Based on the price series, returns were calculated by the logarithmic difference of these prices, totaling 3,230 observations. This period was chosen because it contains turbulence caused by crises, such as the sub-prime and Eurozone ones, as well as calm periods. Aiming to provide some descriptive details of the data used, Figure 1 presents the temporal evolution of log-returns, while Table 2 shows descriptive statistics for this series.

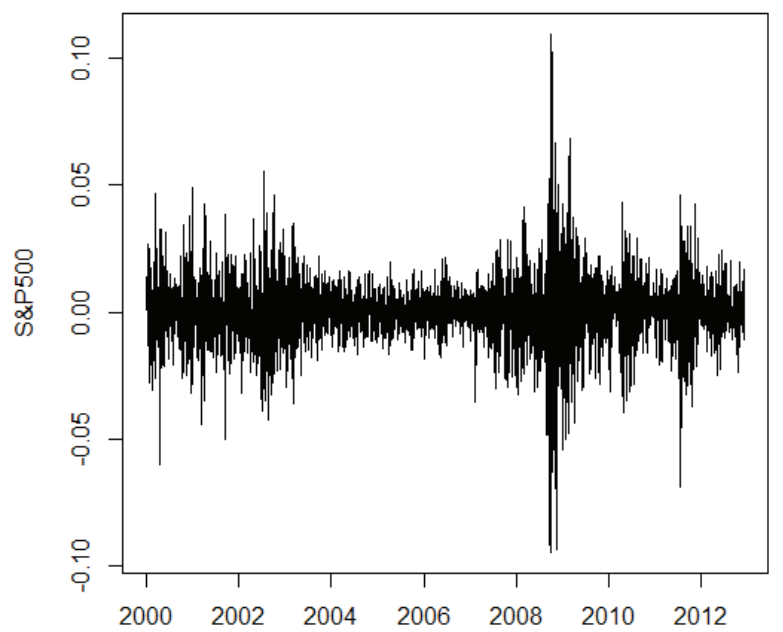

Figure 1. Daily log-returns of S\&P500 from January 2000 to December 2012.

Figure 1 elucidates the presence of turbulent periods that especially coincide with the crises mentioned. These are typical volatility clusters of financial returns. The results in Table 2 emphasize that returns have a close to zero unconditional mean, besides presenting negative asymmetric leptokurtic behavior, as noted by the skewness and kurtosis. The standard deviation, together with the range of returns, points to a volatile pattern during the course of the sample. These are well-known stylized facts of financial assets. To model them, it is necessary to use a model that accommodates these features. A model with unrealistic assumptions about data behavior would compute values that are not close to reality. This may compromise decision-making, leading to losses, which may be irreversible, especially in times of crisis.

Table 2

Descriptive statistics of the daily log-returns of S\&P500 from January 2000 to December 2012

\begin{tabular}{lc}
\hline Statistic & S\&P500 \\
\hline Minimum & -0.0947 \\
Maximum & 0.1096 \\
Mean & 0.0000 \\
Standard Deviation & 0.0135 \\
Skewness & -0.1615 \\
Kurtosis & 10.2856 \\
\hline
\end{tabular}

Although there are many risk models, in this study two models were used that are widely employed in the risk management literature: Historical Simulation (HS) and Filtered Historical Simulation (FHS). See Christoffersen and Gonçalves (2005) and Pritsker (2006). The first model, HS, is related to unrealistic suppositions for data, i.e., the Modernist approach, while the second model, FHS, considers assumptions that are more realistic and is associated with the NeoModernist approach.

Under HS, risk measures forecasts for future date $T$ are calculated directly from a window of the last $N$ observations of raw returns process $\{X\}_{T-N \Delta T}^{T-\Delta T}$, for some interval $\Delta T$, with no filter. This HS estimator is based on historical returns data. There are, as shown by Dowd (2002), many variations of this method, with various advantages and disadvantages. HS assumes returns are independent and identically distributed (i.i.d.), a very restrictive and modernist perspective. Let $E$ be the empirical distribution of returns $\{X\}_{T-N \Delta T}^{T-\Delta T}$. The following is thus obtained: 
$\operatorname{VaR}_{T}^{\alpha}=E^{-1}(\alpha)$, i.e., simply the empirical quantile of returns.

$E S_{T}^{\alpha}=(N \alpha)^{-1} \sum_{i=1}^{N}\left(\{X\}_{T-N \Delta T}^{T-\Delta T} * 1_{\{X\}_{T-N \Delta T}^{T-\Delta T}<V a R_{T}^{\alpha}}\right)$, where $1_{p}$ is the indicator function, which assumes the value 1 if $p$ is true and 0 otherwise. ES is just the mean of values below VaR.

Barone-Adesi, Boutgoin, and Giannopoulos (1998) proposed the conditional flexible approach, called FHS, for VaR estimation. Later, Giannopoulos and Tunaru (2005) extended FHS for ES estimation. Consider that $X$ has a fully parametric location-scale specification based on expectation, dispersion, and random component, in accordance with $X_{T}=\mu_{T}+\sigma_{T} z_{T}$, where, for period $T, X_{T}$ is the random payoff (returns) of an asset or portfolio, $\mu_{T}$ is the conditional mean (location), $\sigma_{T}$ is the conditional standard deviation (scale), and $z_{T}$ represents white noise series with a zero location and unit scale, which can assume many probability distributions functions. The FHS consists of constructing returns series through filtered residuals $\{z\}_{T-N \Delta T}^{T-\Delta T}$ using the conditional mean and volatility predicted for period $T$ that the risk measures estimated, i.e., the series is constructed by $\left\{X^{\prime}\right\}_{T-N \Delta T}^{T-\Delta T}=\mu_{T}+\sigma_{T}\{z\}_{T-N \Delta T}^{T-\Delta T}$. Under this approach, let $E^{\prime}$ be the empirical distribution of constructed returns series $\left\{X^{\prime}\right\}_{T-N \Delta T}^{T-\Delta T}$. The following is thus obtained:

$$
\begin{aligned}
& \operatorname{VaR}_{T}^{\alpha}=E^{\prime-1}(\alpha) \text {, i.e., simply the empirical quantile of }\left\{X^{\prime}\right\}_{T-N \Delta T}^{T-\Delta T} ; \\
& E S_{T}^{\alpha}=(N \alpha)^{-1} \sum_{i=1}^{N}\left(\left\{X^{\prime}\right\}_{T-N \Delta T}^{T-\Delta T} * 1_{\left\{X^{\prime}\right\}_{T-N \Delta T}^{T-\Delta T}<V a R_{T}^{\alpha}}\right) \text {, where } 1_{p} \text { is the indicator function that }
\end{aligned}
$$
assumes the value 1 if $p$ is true and 0 otherwise. ES is just the mean of values below VaR.

Regarding the estimation, $\alpha$ equal to $1 \%$ was employed because this value is most common in the literature and serves practical purposes. It is also recommended by the Basel Committee for the regulation of $\mathrm{VaR}$ (see Basel Committee on Banking Supervision, 2013). The estimation window $N$ was equal to 1,000 days $^{4}$ (four years of daily data). Therefore, the out-of-sample period was composed of 2,230 daily points (full sample with 3,230 observations minus estimation window of 1,000).

Regarding the estimation techniques, for the FHS model, a filter is necessary to model the mean and variance of data conditionally. AR $(m)$ - GARCH $(p, q)$ models $s^{5}$ are estimated in accordance with formulas (3) to (5).

$$
\begin{gathered}
X_{T}=\sum \phi_{m} X_{T-m}+\varepsilon_{T}, \\
\varepsilon_{T}=h_{T} z_{T}, z_{T} \text { skewt }_{v}, \\
h_{T}^{2}=\omega+\sum \alpha_{p} \varepsilon_{T-p}^{2}+\sum \beta_{q} h_{T-q}^{2} .
\end{gathered}
$$

Where, for period $T, X_{T}$ is the log-return of the S\&P500; $h_{T}^{2}$ is the conditional variance; $\phi_{i}, \omega$, $\alpha_{i}$, and $\beta_{i}$ are parameters; $\varepsilon_{T}$ is the innovation in the conditional mean; $z_{T}$ represents a Skewed
Student's $t$ distributed white noise series $\{z\}_{T-N}^{T-1}$. The parameters were estimated using quasimaximum likelihood (QML) to minimize the Gaussian assumption. The number of lags to 
include in the mean and variance equations was selected using the Akaike Information Criterion (AIC). The usual diagnostics were also performed in linear and quadratic standardized residuals, in order to assess if the information is properly filtered.

\section{$3 \cdot 3$ Statistical and paradigmatic comparisons of models}

Figures 2 and 3 show, respectively, the temporal evolution of $\mathrm{VaR}$ and $\mathrm{ES}$ forecasting for the S\&P500 at the $1 \%$ significance level in the out-of-sample period with estimation window $N=1,000$, using unconditional HS and conditional FHS methods. The effect of the 2008 crisis is noted. In this period, a huge fall in the market led to high risk levels, as noted in the four plots. The unconditional HS model reacts badly because the first day of the crisis is not predicted. In addition, after recovery from the crisis, this method maintains a conservative level. These drawbacks are well documented by Pritsker (2006), indicating that HS is not a good choice. Christoffersen and Gonçalves (2005) verify that the HS approach results in bad point estimates for $\mathrm{VaR}$ and $\mathrm{ES}$.

The FHS models have the opposite behavior to the HS one. This model can correctly follow market evolution, considering the crisis but also recovery after it. The great discrepancy is regarding the risk level, since HS exhibits less conservative risk levels than FHS. Thus, as observed, different estimation models lead to discrepant results regarding risk estimation, with a clear advantage going to flexible models compared to unrealistic models, such as HS.

To complement, Figures 4 and 5 present, respectively, the illustration of the densities of $\mathrm{VaR}$ and ES forecasting, considering the same models and conditions as Figures 2 and 3. Negative skewness is observed, which is characteristic of a tail variable, such as a risk measure. The density of the HS estimator has two probability peaks, one for before the crisis period and another for the crisis and post-crisis periods, thus corroborating with Figures 2 and 3. The conditional FHS model has the smoother density plot. Also, the FHS model presents more conservative estimates since low values exhibit probability, while the HS models have a smaller range for their risk predictions.
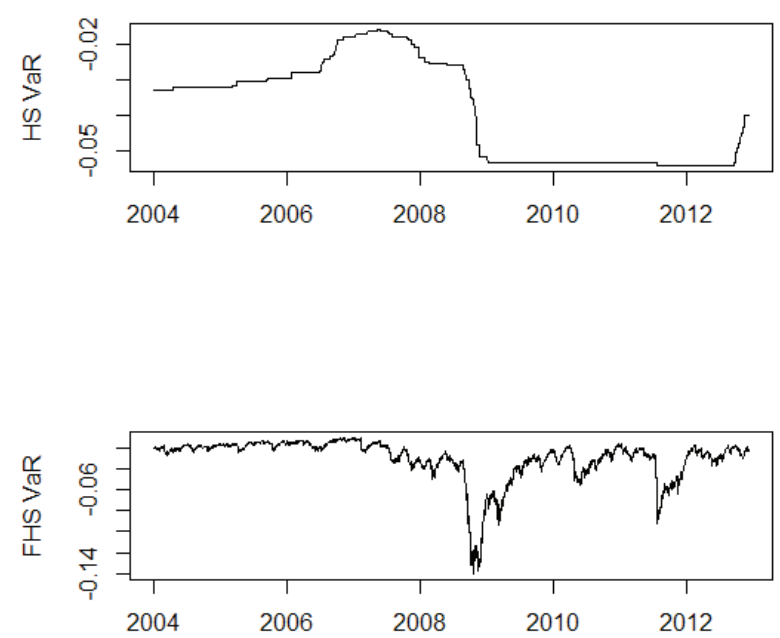

Figure 2. VaR forecasting for S\&P500 at 1\% significance level in out-of-sample period with estimation window $N=1,000$ using unconditional HS and conditional FHS methods.
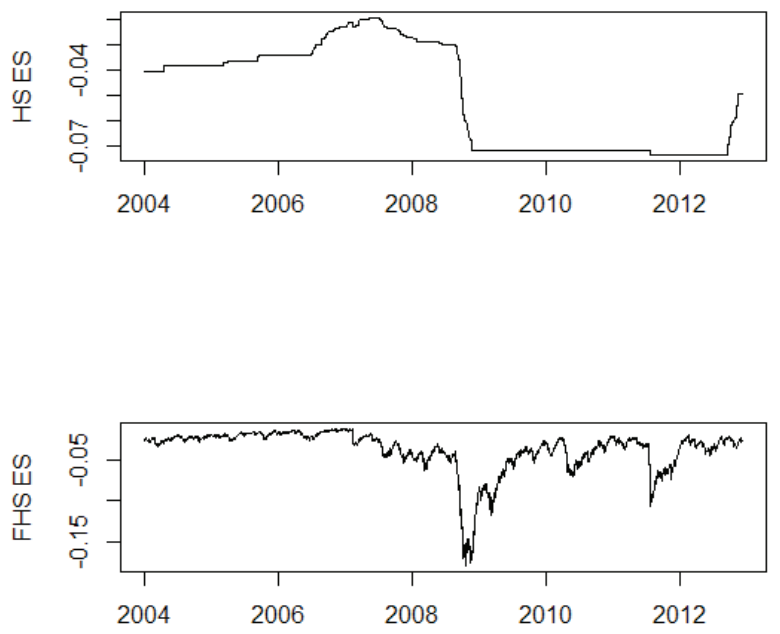

Figure 3. ES forecasting for S\&P500 at 1\% significance level in out-of-sample period with estimation window $N=1,000$ using unconditional HS and conditional FHS methods. 

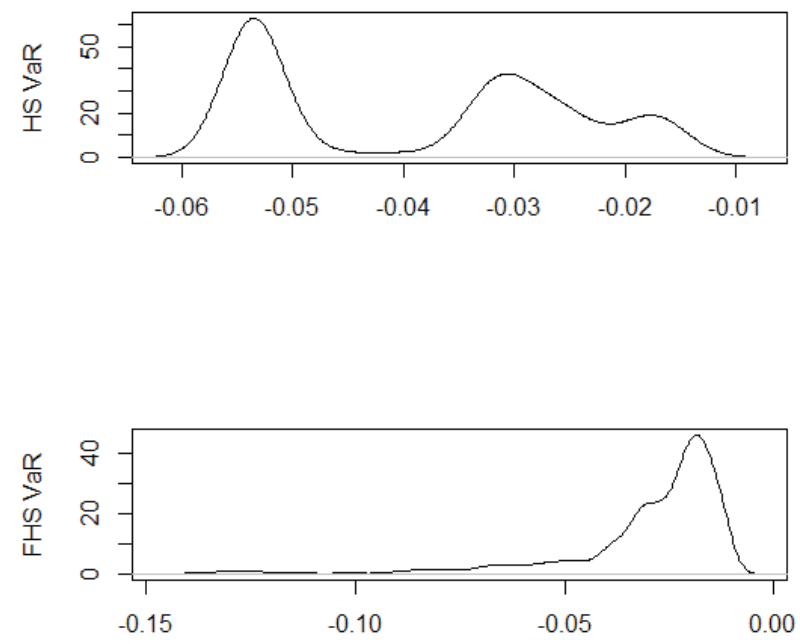

Figure 4. Densities of VaR forecasting for S\&P500 at $1 \%$ significance level in out-of-sample period with estimation window $N=1,000$ using unconditional HS and conditional FHS methods.
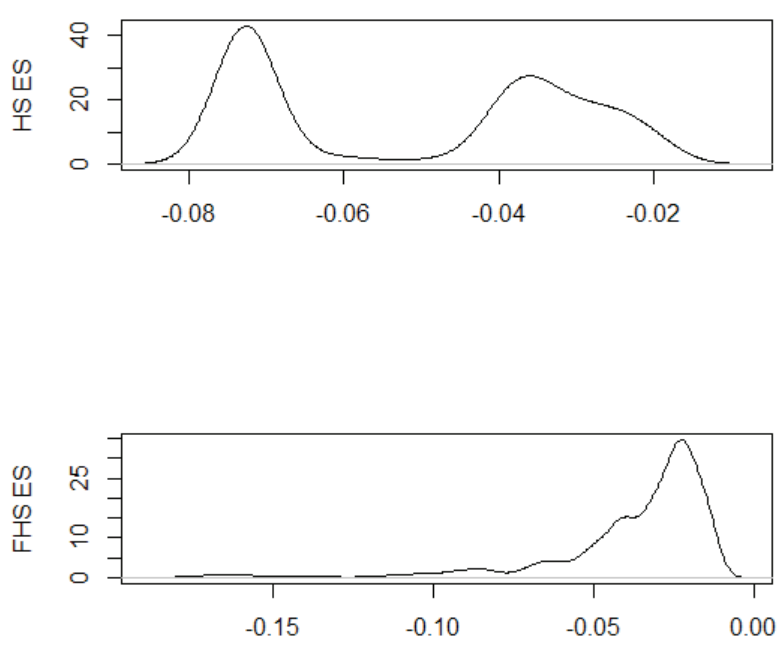

Figure 5. Densities of ES forecasting for S\&P500 at $1 \%$ significance level in out-of-sample period with estimation window $N=1,000$ using unconditional HS and conditional FHS methods.

Concerning the organizational perspective, from the Modernist standpoint, quantification and measurement have become central to risk mapping and risk landscaping techniques, which aim to provide an overall view of the risk profile of an organization. An important sub-dimension of the risk management of everything is the expansion of the domain of rational calculation and modeling to encompass more phenomena that affect organizations. The risk management of everything is closely related to the ambition to measure everything. Versions of it are enshrined and institutionalized in textbooks, forging an intimate conceptual connection between risk and measurable probability. This ideal is often limited in practice (Power, 2011). It is accepted that hazards may be difficult to define, and the data sets supporting probability analysis may be imperfect, but the ideal is clear.

The limitations of the Modernist approach can lead to risk management based on restrictive models. As observed in the analysis, the use of these models, including HS, increases model risk because the forecasts diverge from the observed returns. Corroborating, Chen and Tu (2013), and Müller and Righi (2018) discuss potential losses due to inappropriate returns behavior assumptions that can compromise $\mathrm{VaR}$ and ES forecasting. In addition to financial losses, using an inefficient asset allocation and incorrect capital requirement, for example, can result in poor strategic decision-making, and damage the reputation of the institution (Federal Reserve, 2011).

As an alternative to Modernism, the Postmodernist paradigm arises, questioning this need for measurement. From this perspective, the idea of risk measurement by itself is wrong. One argument is that the process of aggregation by which individual heuristics become collective market phenomena is not generally addressed. The distribution and timing of anomalies cannot easily be predicted. The financial system only seemed safe because each firm or unit could demonstrate extensive audit trails of compliance and risk management to the regulator, a symbolic, but not real, risk management. LaPorte (2007) argues that institutional norms and processes that in calmer times act to facilitate public functions become inhibitors to fashioning novel responses in times of crisis, when flexibility and improvisation are in order. In addition, Power (1997) argues that a society that seems to manage risk via the 
intensification of auditing and monitoring only makes itself more vulnerable.

Regarding this matter, Haldane (2013) highlights that feedback effects under stress and the complexity and dimensionality of the network further increase uncertainty, a tendency exacerbated by financial innovation. The result is that financial diversification strategies have achieved the opposite of risk reduction because of a loss of diversity of business models and related risk management practices. It is only when a large or connected financial institution is subject to stress that network dynamics will be properly unearthed.

However, the argumentation about the limitations of the Modernist approach does not invalidate the measurement and modeling of risk. This reflection leads to the need for a proper measurement, rather than a restrictive one. Flexible and realistic estimation models need to be developed and used by institutions. Thus, an alternative way to reduce the problem of model risk is to use a conditional FHS model for VaR and ES estimation, because it is a good example of a successful approach, according to the results of this study. From an organizational point of view, for financial risk management, what appears to be most appropriate is an improvement of the Modernist paradigm, rather than the breakthrough proposed by Postmodernism. This much needed paradigm is the well-known Neomodernism.

Neo-modernism has developed in several different forms, but perhaps it is key achievement is the notion that one can combine insights from social sciences, and the rigor of the methods associated with these social sciences, and integrate them through the lens of humanistic philosophy to develop organizations. As confirmed by the empirical results, intelligent risk management will embed quantitative techniques in learning processes and diagnostics, whereby retrospective accident and error analysis can be harnessed for future planning.

\section{Conclusion}

This paper establishes a connection between the assumptions of risk models and the paradigms of organizational studies. To achieve the goal, a discussion was presented on risk in organizations, based on organizational studies. Additionally, an illustration was presented, containing two risk models, HS and FHS, in order to establish the impact of unrealistic assumptions on risk management results. From the organizational studies point of view, the restrictive models supported by Modernist thought are not the most suitable for financial risk management. The absolute lack of measurement of the Postmodernist paradigm may be too radical in the sense that, in the practical field, there is a crucial need for quantitative information to allow financial institutions and investors to protect their investments.

Such protection is only possible through precise estimates obtained from models that properly consider the stylized facts present in financial series. Therefore, for financial risk management, it is more interesting to improve the Modernist paradigm, rather than negating it with a Postmodernist approach. The solution is the Neo-modernist paradigm, which can combine insights from social science and the rigor of traditional methods and possibly reduce model risk.

Hence, the proposed objective was accomplished, and the main contribution of the study was achieved, i.e., raising the influence of other attributes of financial risk estimation that go beyond mathematical and statistical grounds. To do that, it was shown that the traditional literature on financial risk management estimation is influenced, although subliminally, by sociological issues from the literature on organizational studies. This paper is the first to try and to connect these two fields of research. For future research, we recommend exploring this relationship, comparing other models and assets, or more deeply analyzing the evolution of 
the scientific and philosophical thought behind the field of risk management.

\section{References}

Acerbi, C., \& Tasche, D. (2002). On the coherence of expected shortfall. Journal of Banking \& Finance, 26(7), 1487-1503.

Alexander, C., \& Sheedy, E. (2008). Developing a stress testing framework based on market risk models. Journal of Banking \& Finance, 32, 2220-2236.

Artzner, P., Delbaen, F., Eber, J.-M., \& Heath, D. (1999). Coherent measure of risk. Mathematical Finance, 9(3), 203-228.

Barone-Adesi, G., Boutgoin, F., \& Giannopoulos, K. (1998). Don't look back. Risk, 11(8), 31-58.

Basel Committee on Banking Supervision (2013). Fundamental review of the trading book: $A$ revised market risk framework. Switzerland: Bank for International Settlements.

Beck, U. (1992). Risk society: Towards a new modernity (Vol. 17). London: Sage.

Beck, U., \& Holzer, B. (2007). Organizations in world risk society. In C. M. Pearson, C. RouxDufort, \& J. A. Clair, International handbook of organizational crisis management. Thousand Oaks, CA: Sage Publications.

Berkowitz, J., Christoffersen, P., \& Pelletier, D. (2011). Evaluating value-at-risk models with desk-level data. Journal Management Science Archive, 57(12), 2213-2227.

Berkowitz, J., \& O’Brien, J. (2002). How accurate are value-at-risk models at commercial banks? Journal of Finance, 57, 1093-1111.

Boucher, C. M., Daníelsson, J., Kouontchou, P. S., \& Maillet, B. B. (2014). Risk model-at-risk. Journal of Banking \& Finance, 44, 72-92.
Castel, R. (1991). From dangerousness to risk. In G. Burchell, C. Gordon, \& P. Miller (eds.). The Foucault effect: Studies in governmentality. London: Harvester/Wheatsheaf.

Chen, Y.-H., \& Tu, A. H. (2013). Estimating hedged portfolio value-at-risk using the conditional copula: An illustration of model risk. International Review of Economics \& Finance, 27, 514-528.

Christoffersen, P., \& Gonçalves, S. (2005). Estimation risk in financial risk management. Journal of Risk, 7(3), 1-27.

Coles, E., Smith, D., \& Tombs, S. (2000). Risk management and society. London: Kluwer.

Daníelsson, J. (2008). Blame the models. Journal of Financial Stability, 4(4), 321-328.

Daníelsson, J. (2002). The emperor no clothes: Limits to risk modelling. Journal of Banking \& Finance, 26, 1273-1296.

Daníelsson, J., James, K. R., Valenzuela, M., \& Zer, I. (2016). Model risk of risk models. Journal of Financial Stability, 23, 79-91.

Daníelsson, J., \& Shin, H. S. (2003). Endogenous Risk. In P. Field (ed.), Modern Risk Management: A History (pp. 297-314). London: Risk Books.

Dean, M. (1999). Risk, calculable and incalculable, In D. Lupton (ed.). Risk and sociocultural theory: New directions and perspectives. Cambridge: Cambridge University Press.

Douglas, M., \& Wildavsky, A. (1982). Risk and culture: An essay on the selection of technical and environmental dangers. Berkeley: University of California Press.

Dowd, K. (2002). Measuring market risk. New York: Wiley Finance.

Federal Reserve. (2011). Supervisory guidance on model risk management: Board of Governors of 
the Federal Reserve System, Oce of the Comptroller of the Currency. Retrieved from https://www. federalreserve.gov/supervisionreg/srletters/ sr1107a1.pdf

Fissler, T., \& Ziegel, J. F. (2016). Higher order elicitability and Osband's principle. The Annals of Statistics, 44(4), 1680-1707.

Föllmer, H., \& Weber, S. (2015). The axiomatic approach to risk measures for capital determination. Annual Review of Financial Economics, 7, 301-337.

Gephart, R. P., Maanen, V. J., \& Oberlechner, T. (2009). Organizations and risk in late modernity. Organization Studies, 30(02-03), 141-155.

Giannopoulos, K., \& Tunaru, R. (2005). Coherent risk measurement under filtered historical simulation. Journal of Banking and Finance, 29, 979-996.

Giddens, A. (2013). The consequences of modernity. New York: John Wiley \& Sons.

Goede, M. (2004). Repoliticizing financial risk. Economy and Society, 33(2), 197-217.

Miller, K. D. (2009). Organizational risk after modernism. Organization Studies, 30, 157-180.

Kuester, K., Mittnik, S., \& Paolella, M. S. (2006). Value-at-Risk prediction: A comparison of alternative strategies. Journal of Financial Econometrics, 4, 53-89.

Kunreuther, H., \& Slovic, P. (1996). Challenges in risk assessment and risk management. The Annals of the American Academy of Political and Social Science (Vol. 545). Thousand Oaks, CA: Sage.

Haldane, A. G. (2013). Rethinking the financial network. In S. A. Jansen, E. Schröter, N. Stehr. Fragile stabilität-stabile fragilität. Springer: Wiesbaden, p. 243-278.

Hutter, B., \& Power, M. (2005). Organizational encounters with risk: An introduction. Cambridge: Cambridge University Press.
LaPorte, T. R. (2007). Critical infrastructure in the face of a predatory future: Preparing for untoward surprise. Journal of Contingencies and Crisis Management, 15(1), 60-64.

Lee, Y., Kozar, K. A., \& Larsen, K. (2003). The technology acceptance model: Past, present, and future. Communications of the Association for Information Systems, 12(50), 752-780.

Lubatkin, M., \& Rogers, R. C. (1989). Diversification, sistematic risk, and shareholder return: A capitel market extencion of rumelt's 1974 study. Academy of Management Journal, 32(2), 454-465.

Luhmann, N. (1998). Observations on modernity. Stanford, CA: Stanford University.

Lupton, D. (1999). Risk. London: Routledge.

Lyotard, J.-F. (1984). The postmodern condition: A report on knowledge (Theory and History of Literature, Vol. 10). Minnesota: University of Minnesota Press.

Mirchandani, R. (2005). Postmodernism and sociology: From the epistemological to the empirical. Sociological Theory, 23(1), 86-115.

Mythen, G. (2008). Sociology and the art of risk. Sociology Compass, 2(1), 299-316.

Müller, F. M., \& Righi, M. B. (2018). Numerical comparison of multivariate models to forecasting risk measures. Risk Management, 20(1), 29-50.

Pérignon, C., \& Smith, D. R. (2010). The level and quality of value-at-risk disclosure by commercial banks. Journal of Banking \& Finance, 34(2), 362-377.

Pérignon, C., Deng, Z. Y., \& Wang, Z. Y. (2008). Do banks overstate their value-at-risk? Journal of Banking \& Finance, 32(5), 783-794.

Power, M. (1997). The audit society: Rituals of verification. Oxford: Oxford University Press. 
Power, M. (2004). The risk management of everything. Journal of Risk Finance, 5(3), 58-65.

Power, M. (2007). Organized uncertainty: Designing a world of risk management. Oxford: Oxford University Press.

Power, M. (2011). Preparing for financial surprise. Journal of Contingencies and Crisis Management, 19, 1-4.

Pritsker, M. (2006). The hidden dangers of historical simulation. Journal of Banking and Finance, 30, 561-582.

Rockafellar, T. R., \& Uryasev, S. (2002). Conditional value-at-risk for general loss distributions. Journal of Banking and Finance, 26(7), 1443-1471.

Rothstein, H., Huber, M., \& Gaskell, G. (2006). A theory of risk colonization: The spiralling regulatory logics of societal and institutional risk. Economy and Society, 35(1), 91-112.
Scheytt, T., Soin, K., Sahlin-Andersson, K., \& Power, M. (2006). Introduction: Organizations, risk and regulation. Journal of Management Studies, 43(6), 1331-1337.

Schrag, C. O. (1989). Rationality between modernity and Postmodernity. In F. R. S. Dallmayr, \& K. White. Life-world and politics: Between modernity and Postmodernity: Essays in honor of (ed.), 81-106. Notre Dame: University of Notre Dame Press.

Tasche, D. (2002). Expected shortfall and beyond. Journal of Banking \& Finance, 26, 1519-1533.

Tversky, A., \& Kahneman, D. (1974). Judgment under uncertainty: Heuristics and biases. Science, New Series, 185(4157), 1124-1131.

Woo, C. Y., \& Cool, K. O. (1990). The impact of strategic management on systematic risk. In P. Shrivastava, \& R. B. Lamb. Advances in strategic management, 6, 51-69.

\section{Notes}

1 Risk measures are estimated from historical data; it is important to compare competing estimation procedures. When the verification and comparison of competing estimation procedures is possible, risk measures are called elicitable (Fissler $\&$ Ziegel, 2016).

2 In the sense proposed by Artzner et al. (1999), a coherent risk measure satisfies four axioms: translation invariance, subadditivity, positive homogeneity, and monotonicity. VaR does not respect subadditivity, thus the VaR of a portfolio is not necessarily smaller or equal to the sum of the $\mathrm{VaR}$ for individual assets.

3 The S\&P500 index was employed because it is one of the most used in financial studies.

4 The literature demonstrates 1,000 observations is a good estimation sample size for daily data.

5 Risk measures are estimated with other GARCH type models, including GJR-GARCH, EGARCH, and APARCH; however, in general, the GARCH model with skewed Student's $t$ innovations has the best performance, considering selection criteria and data filtering efficiency, as well as its parsimony. 


\section{Supporting Agencies:}

Coordenação de Aperfeiçoamento de Pessoal de Nível Superior (CAPES) and Fundação de Amparo à Pesquisa do Estado do Rio Grande do Sul (FAPERGS)

\section{About the Authors:}

1. Marcelo Brutti Righi, PhD in Finance, Federal University of Santa Maria, Santa Maria, Brazil.

E-mail: marcelo.righi@ufrgs.br

ORCID

(iD0000-0002-3753-0705

2. Fernanda Maria Müller, PhD Student in Finance, Federal University of Rio Grande do Sul, Porto Alegre, Brazil. E-mail: fernanda.muller@ufrgs.br

ORCID

(D)0000-0001-9929-427X

3.Vinícius Girardi da Silveira, Master's Degree in Finance, Federal University of Santa Maria, Santa Maria, Brazil. E-mail: vinicius.girardi@hotmail.com

ORCID

(iD) 0000-0002-1774-5661

4. Kelmara Mendes Vieira, PhD in Finance, Federal University of Rio Grande do Sul, Porto Alegre, Brazil. E-mail:kelmara@terra.com.br.

ORCID

(iD)0000-0002-8847-0941

\section{Contribution of each author:}

\begin{tabular}{|c|c|c|c|c|}
\hline Contribution & $\begin{array}{c}\text { Marcelo } \\
\text { Brutti Righi }\end{array}$ & $\begin{array}{c}\text { Fernanda } \\
\text { Maria Müller }\end{array}$ & $\begin{array}{l}\text { Vinícius Girardi } \\
\text { da Silveira }\end{array}$ & $\begin{array}{c}\text { Kelmara } \\
\text { Mendes Vieira }\end{array}$ \\
\hline 1. Definition of research problem & $\sqrt{ }$ & & & $\sqrt{ }$ \\
\hline $\begin{array}{l}\text { 2. Development of hypotheses or research questions } \\
\text { (empirical studies) }\end{array}$ & $\sqrt{ }$ & & & $\sqrt{ }$ \\
\hline 3. Development of theoretical propositions (theoretical work) & $\sqrt{ }$ & & & \\
\hline 4. Theoretical foundation/Literature review & $\sqrt{ }$ & & & \\
\hline 5. Definition of methodological procedures & $\sqrt{ }$ & $\sqrt{ }$ & & \\
\hline 6. Data collection & $\sqrt{ }$ & $\sqrt{ }$ & & \\
\hline 7. Statistical analysis & $\sqrt{ }$ & $\sqrt{ }$ & & \\
\hline 8. Analysis and interpretation of data & $\sqrt{ }$ & $\sqrt{ }$ & $\sqrt{ }$ & \\
\hline 9. Critical revision of the manuscript & $\sqrt{ }$ & $\sqrt{ }$ & $\sqrt{ }$ & \\
\hline 10. Manuscript writing & $\sqrt{ }$ & $\sqrt{ }$ & $\sqrt{ }$ & $\sqrt{ }$ \\
\hline 11. Other (please specify which) & $\sqrt{ }$ & $\sqrt{ }$ & $\sqrt{ }$ & $\sqrt{ }$ \\
\hline
\end{tabular}

